\title{
Theoretical Study of the Effect of High Pressure on the Elastic and the Thermal Properties of MgO
}

\author{
Janan F. A. Ali \\ Department of Physics/ College of Education for Pure Science / University of Mosul \\ E-mail: jananfakhre@gmail.com
}

(Received 5/5/2019 ; Accepted 19/1/2020)

DOI: $\underline{\text { 10.33899/rjj.2020.164475 }}$

\begin{abstract}
Elastic-Thermo properties of alkaline earth oxide $\mathrm{MgO}$ have been studied by using two types of Equation of State ( EOS ), Isothermal Shanker EOS and Modified Kumar EOS.

The elastic moduli, sound velocities and the pressure-compression relationship of $\mathrm{MgO}$ have been studied up to a pressure $150 \mathrm{GPa}$ by using Shanker EOS which depends on volume shortrange force constant of inter atomic potentials. The results show agreement with the researcher results Upadhyay and Sharma.

The relationship between the solid density and elastic moduli gave values both of compression and shear waves velocities, the theoretical results are below rate about $6 \%$ with the whole range of the experimental data.

The thermal properties at high( temperature and pressure) of $\mathrm{MgO}$ have been studied by applying unified theory of Kumar EOS, this theory based on thermodynamic analysis and to the thermal expansion,thus the inharmonic term is arising and used in the calculation of thermal properties of $\mathrm{MgO}$.

The results which are obtained from the effect of high temperature and high pressure on $\mathrm{MgO}$ properties are fitting with an experimental data.
\end{abstract}

Keywords: $\mathrm{MgO}$, elastic moduli, thermal properties under high pressure, equation of state (EOS).

\section{INTRODUCTION}

$\mathrm{MgO}$ is one of geophysical minerals which are constituents of earth lower mantle core and it is a simple oxide with cubic $\mathrm{NaCl}$ structure (Gaudoiu and Foulkes, 2002).

Equation of state (EOS) is a useful equation describing the state and properties of matter under a given set of physical conditions such as temperature, pressure, specific volume and internal energy. This study is resting on the EOS which are important in physics and earth sciences. Various equation of state are intended to account for the volumetric properties of $\mathrm{MgO}$ whose structure configuration varies with pressure and temperature.

The present study consists of two parts. firstly; Isothermal Shanker EOS (Born and Huang 1954); (Poirier, 2000) which is used to evaluate the elastic modules [shear ( $\mathrm{G})$, bulk $(\mathrm{K})$, young (y)], poison's ratio and solid sound velocities of $\mathrm{MgO}$ at high pressure (Singh et al.,2007), secondly; Modified Kumar EOS (Kumar, 2002); (Joshi and Gupta, 2007) is used to calculate the effect of high temperature and pressure on thermodynamic properties of $\mathrm{MgO}$. The results are in agreement with the researcher results of (Upadhyay and sharma , 2011 )

Theory

The EOS is considered useful for researches and numerous important applications. The behavior of metals and materials at normal pressure and temperature is much different than at high pressure and temperature. 


\section{1- Shanker EOS}

Shanker had obtained an EOS using the volume dependence of short-range force constant for inter atomic potentials (Born and Huang, 1954; Poirer, 2000). The definition of the short-range force constant as follows

$$
\mathrm{F}=(2 / 3)\left[\frac{\delta^{2} E}{\delta r^{2}}+\frac{2 \delta E}{r \delta r}\right]
$$

where $\mathrm{E}$ is the potential energy of lattice. The expressions based on the Shanker EOS are given below.

$$
\begin{aligned}
& \left.\mathrm{P}=\mathrm{K}_{\mathrm{o}} \frac{x^{-4 / s}}{t}\left[\left(1-\frac{1}{t}+\frac{2}{t 2}\right)\{\exp (\text { ty })-1\}+\mathrm{y}\left(1+\mathrm{y}-\frac{2}{t}\right)\right] \exp (\text { ty })\right] \\
& \mathrm{K}=\mathrm{K}_{\mathrm{o}} \mathrm{x}^{(-1 / 3)}\left(1+\mathrm{y}+\mathrm{y}^{2}\right) \exp (\mathrm{ty})+(4 / 3) \mathrm{P} \\
& \mathrm{K}^{-}=(4 / 3)+\left(1-\frac{4 P}{3 K}\right)[1 / 3+\mathrm{x}\{t+(1+2 y) /(1+y+y \ldots \ldots \ldots \ldots \ldots \ldots \ldots \ldots \ldots \ldots \ldots \ldots \ldots
\end{aligned}
$$

Where; $\mathrm{p}$ is the pressure, $\mathrm{K}$ is isothermal bulk modulus, $\mathrm{K}^{-}$is the derivatives bulk modulus with pressure.

$\mathrm{K}^{-}=\mathrm{dK} / \mathrm{dP}, \mathrm{t}=\mathrm{K}_{\mathrm{o}}^{-}-(8 / 3), \mathrm{y}=1-\mathrm{V} / \mathrm{V}_{\mathrm{o}}, \mathrm{x}=\mathrm{V} / \mathrm{V}_{\mathrm{o}}, \mathrm{V}_{\mathrm{o}}$ is the volume at room temperature and atmospheric pressure, then the relationships between pressure and density are determined with the help of Shanker EOS where $\mathrm{x}=\mathrm{V} / \mathrm{V}_{\mathrm{o}}=\rho_{\mathrm{o}} / \rho$.

\section{2- Elastic Moduli of MgO}

The elastic moduli (Singh et al., 2007) are

a.

bulk modulus $(\mathrm{K})$ is defined in eq.

b.

$(3 / 5)(\mathrm{K}-2 \mathrm{P})$ Shear Modulus

(5)

c.

$(9 \mathrm{KG}) /(3 \mathrm{~K}+\mathrm{G})$ young modulus

(6)

d.

$(3 \mathrm{~K}+4 \mathrm{P}) /(12 \mathrm{~K}-4 \mathrm{P})$ poisson's ratio

The above equations are used to calculate all of isothermal (bulk, shear, young) moduli and poisson's ratio with help of $\mathrm{K}$ and $\mathrm{P}$ as functions of density. The results for these elastic moduli are used to calculate the sound velocity of the solid and compared with experimental data (Chopelas $e t$ al., 1996),

There are mainly two types of sound velocity $v_{\mathrm{p}}$ and $v_{\mathrm{s}}$; longitudinal and transverse waves. They are related to bulk $(K)$, shear $(G)$, density $(\rho)$ as follows (Upadhyay and Sharma,2011);

$$
\begin{aligned}
& v_{\mathrm{p}}=\left[\frac{\left(K+\frac{4}{\mathrm{~g}} G\right)}{\mathrm{p}}\right]^{0.5} \\
& v_{\mathrm{s}}=(\mathrm{G} / \mathrm{\rho})^{1 / 2}
\end{aligned}
$$

\section{3- Thermal-physical properties}

Kumar EOS (Kumar, 2002) is defined as:

$$
\frac{V_{p}}{V_{\mathrm{o}}}=1-\frac{1}{A} \ln \left[1-\frac{A}{K_{\mathrm{a}}}\left\{\alpha_{\mathrm{o}} K_{\mathrm{o}}(\mathrm{T}-\mathrm{To})-\mathrm{P}\right\}\right]
$$

The inverted isobaric Kumar EOS is based on the sound thermodynamic analysis which depends on Anderson Grunesion parameter $\left(\boldsymbol{\delta}^{\mathbf{0}}\right)$. and $\delta^{\mathrm{o}}$ here is independent on temperature, $\alpha_{\mathrm{o}}$ is thermal expansion coefficient at $\mathrm{T}_{\mathrm{o}}$ Where $\mathrm{A}$ is a parameter $=\delta^{\mathrm{o}}+1=\mathrm{K}_{\mathrm{o}}^{-}+1$,

Follow (Kumar, 2002), (Singh, 2001) and (Singh and Kumar, 2004 ) gave the relations for the-thermo-elastic properties which changes at high temperatures and high pressure, the thermal properties are thermal (pressure, volume, expansion coefficient, bulk modulus) and defined as:

The thermal pressure is a physical quantity of central importance for investigating the thermoelastic properties of materials at high temperature (Ahmad and Mahmood;2017) and defined by: 
$\mathrm{P}_{\mathrm{th}}=\alpha_{\mathrm{o}} \mathrm{K}_{\mathrm{o}}\left(\mathrm{T}-\mathrm{T}_{\mathrm{o}}\right)$

By taking the approximation that $\alpha \mathrm{k}$ is independent of temperature, this gives:

$\alpha \mathrm{k}=\alpha_{0} \mathrm{~K}_{\mathrm{o}}$

and by expanding eq.(10) and considering the terms up to third order, the high order-term of eq.(10) can be written as follows:

$$
\frac{V p}{V_{o}}=1+\frac{1}{A}\left[e^{\left(\alpha_{o} \mathrm{~A}\left(\mathrm{~T}-\mathrm{T}_{\mathrm{o}}\right)-\frac{\mathrm{AP}}{\mathrm{K}_{\mathrm{z}}}\right)}-1+\frac{1}{6}\left\{\alpha_{0} A\left(T-T_{\mathrm{o}}\right)-P A / K_{0}\right\}^{3}\right] .
$$

Where $\frac{V p}{V_{s}}$ are the thermal volume

The thermal expansion coefficient is defined as follows

$$
\begin{aligned}
& \alpha=\left(\frac{1}{v}\right)\left(\delta \mathrm{v} / \delta_{\mathrm{T}}\right)_{\mathrm{P}}
\end{aligned}
$$

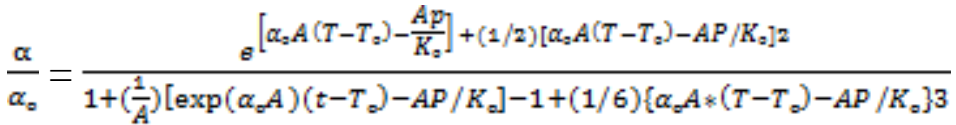

The bulk modulus is defined as follows

$\mathrm{K}=-\mathrm{V}_{\mathrm{o}}(\delta \mathrm{P} / \delta \mathrm{V})_{\mathrm{T}}$

The thermal bulk modulus ratio can be rewritten as:

$$
\frac{K}{K_{z}}=\frac{1+\frac{1}{A}\left[e^{\left(\alpha_{z} A\left(T-T_{z}\right)-\frac{A P}{K_{z}}\right)}-1+\frac{1}{6}\left[\alpha_{z} A\left(T-T_{p}\right)-P A / K_{p}\right] 3\right]}{e^{\left[\alpha_{z} A\left(T-T_{z}\right)-\frac{A P}{K_{z}}\right]+(1 / 2)\left[\alpha_{z} A\left(T-T_{z}\right)-A P / K_{z}\right] 2}}
$$

\section{Elastic Results}

\section{RESULT AND DISCUSSION}

The input parameters used in calculations are $\rho_{\mathrm{o}}=3.523 \mathrm{~g} / \mathrm{cm}^{3}, \mathrm{~K}_{\mathrm{o}}=159.67 \mathrm{Gpa}, \mathrm{K}_{\mathrm{o}}^{-}=4.13, v_{\mathrm{p}}$ $=9$ at To $=298$ Kelvin, and $v_{\mathrm{s}}=5$. (Chopelas et al., 1996). Table (1) shows the experimental data (Upadhyay and Sharma, 2011).

\section{Table 1: Input experimental data}

\begin{tabular}{|c|c|c|}
\hline $\mathrm{V} / \mathrm{V}_{\mathrm{o}}$ & $\rho\left(\mathrm{g} / \mathrm{cm}^{3}\right)$ & $\rho / \rho_{\mathrm{o}}$ \\
\hline 1 & 3.583 & 1 \\
\hline 0.95 & 3.772 & 1.05 \\
\hline 0.9 & 3.981 & 1.4 \\
\hline 0.85 & 4.125 & 1.18 \\
\hline 0.8 & 4.479 & 1.25 \\
\hline 0.75 & 4.777 & 1.33 \\
\hline 0.7 & 5.119 & 1.41 \\
\hline 0.65 & 5.512 & 1.54 \\
\hline
\end{tabular}

The results of elastic properties for $\mathrm{MgO}$ which are based on the Shanker EOS are shown in Figs.(1-7). 


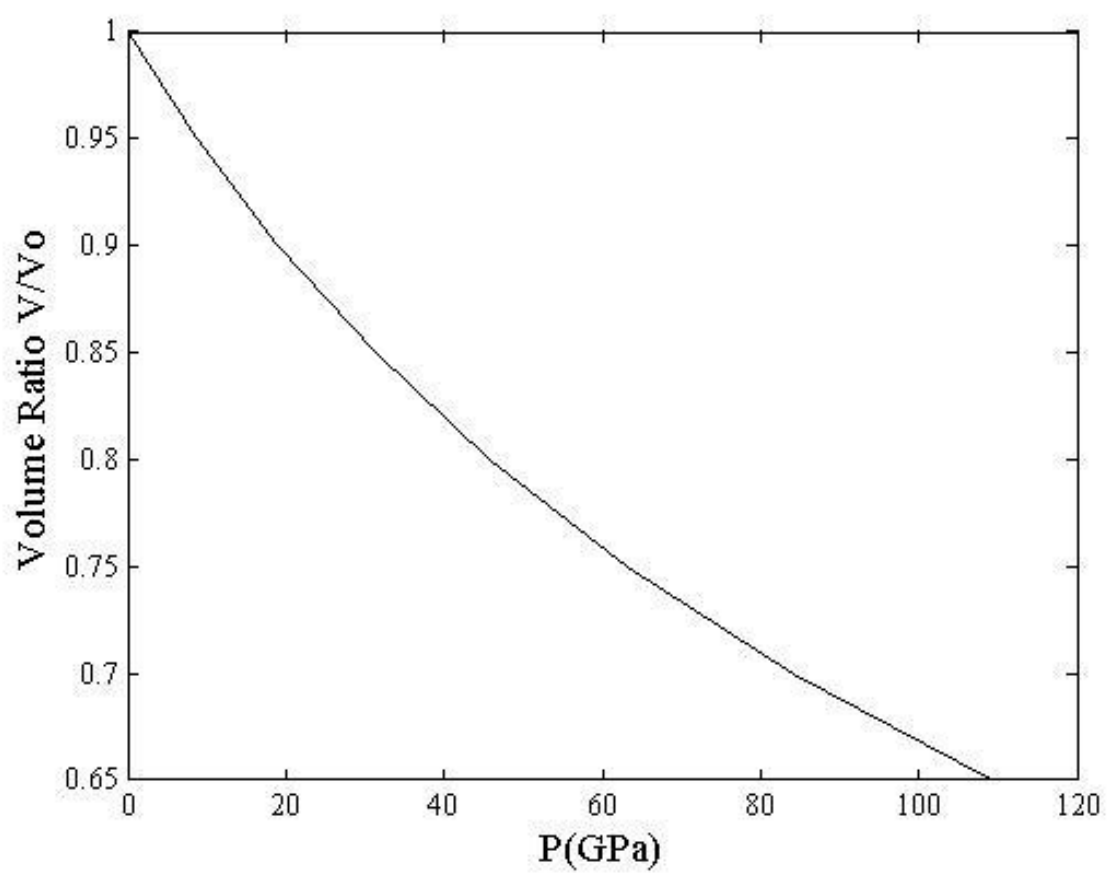

Fig. 1: The compressibility curve for MgO

Fig. (1) gives relation between $\mathrm{V} / \mathrm{V}_{\mathrm{o}}$ from range (1-0.65) and pressure (110GPa).

The elastic moduli ( $\mathrm{G}$ shear modulus, $\mathrm{Y}$ young modulus) and Poisson's ratio are calculated with the help of $\mathrm{K}$ and $\mathrm{P}$ as a function of density by using equations (2-7) and drawn up in Fig.(2).

Fig. (2) (a, b, c ) shows that $(K, Y, G)$ increases with the increase of the pressure and density, and shows the nature of moduli are similar to that of bulk modulus, they increases linearly while Fig. (2d) of the poison's ratio with pressure is gradually increased, and then the variation is small.
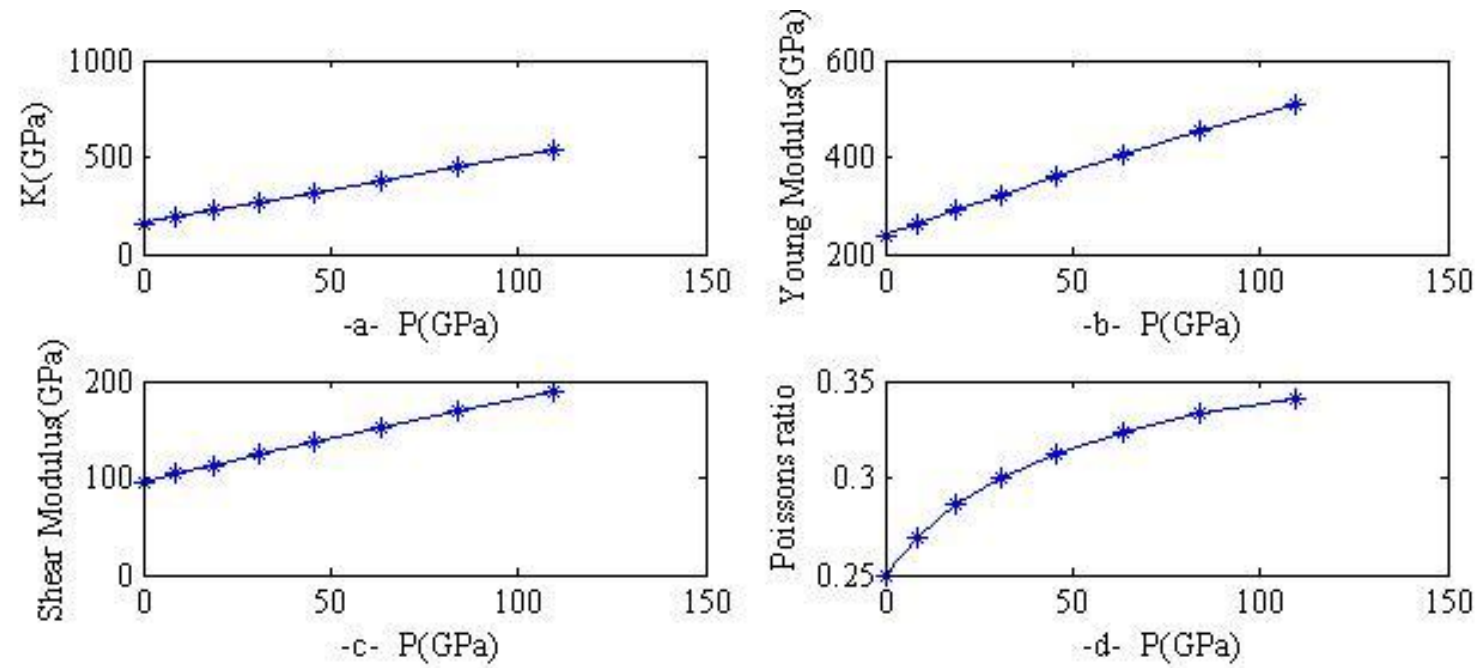

Fig. 2: Comparison of calculated elastic moduli with the resercher Results of (Upadhyay and Sharma, 2011)

These moduli for $\mathrm{MgO}$ which are based on Shanker EOS (2) are increased linearly with the increase of the pressure and density and in good agreement with the researcher results of (Upadhyay and Sharma, 2011). The compressional (longitudinal) and the shear (transverse) 
velocities are increased with the increasing pressure as in Figs. $(3,4)$. The calculated velocity values are below- rate about $6 \%$ compared with the whole range of available experimental data, this mean that compressional and shear equations are needed another parameter to give good fitting.

Also this mean that Shanker EOS is expected to give results to a greater value of accuracy at zero pressure and deviation may occur at high pressure, and the deviation is almost constant and the average value of increasing of longitudinal value with the increase of pressure is faster than that of transverse velocity. The relation between density and pressure is shown in Fig. (7).

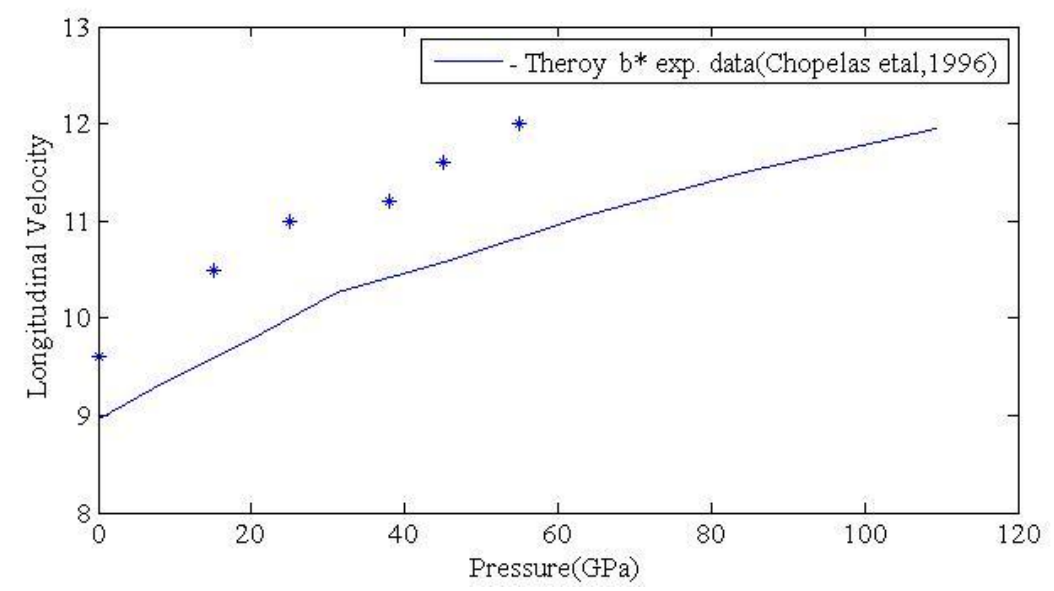

Fig. 3: The variation of longitudinal velocity with pressure

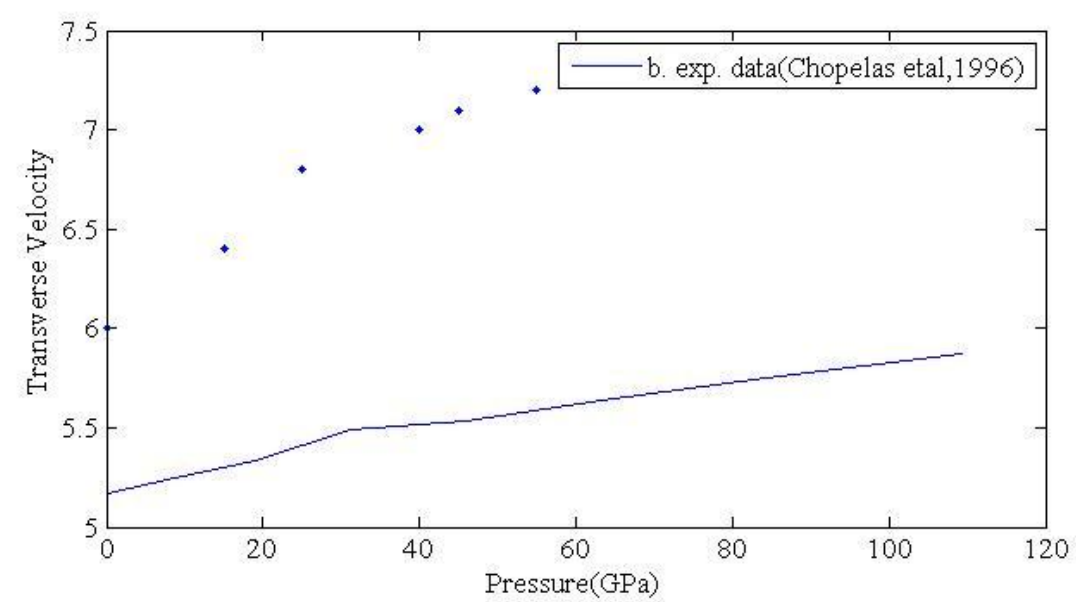

Fig. 4: Variation of transverse velocity with pressure.

The results for sound velocities ratio with density are shown in Figs. (5,6 ). 


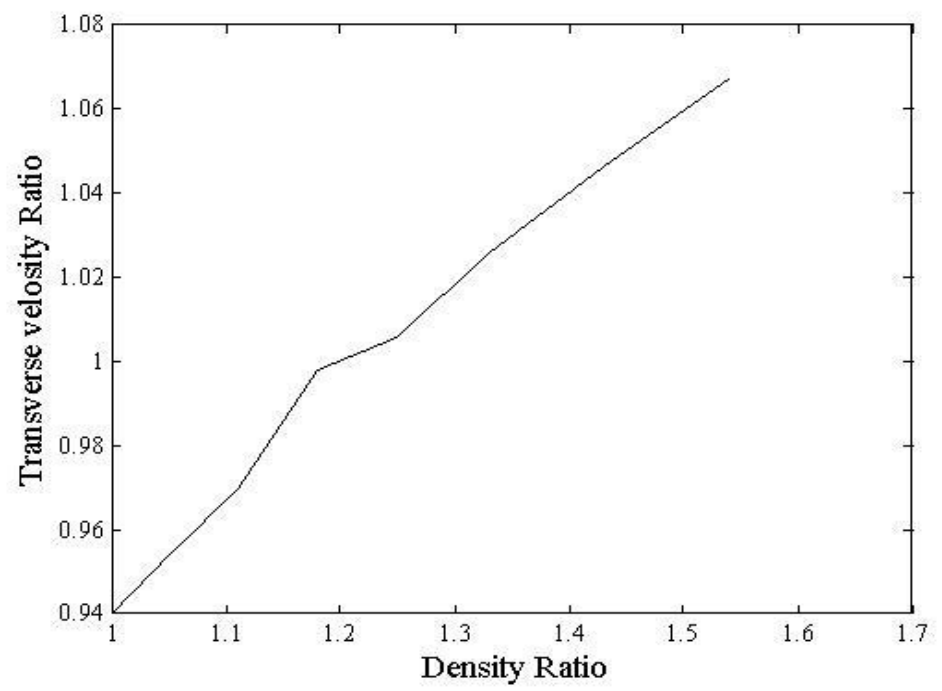

Fig. 5: Variation of transverse velocity ratio with Density ratio

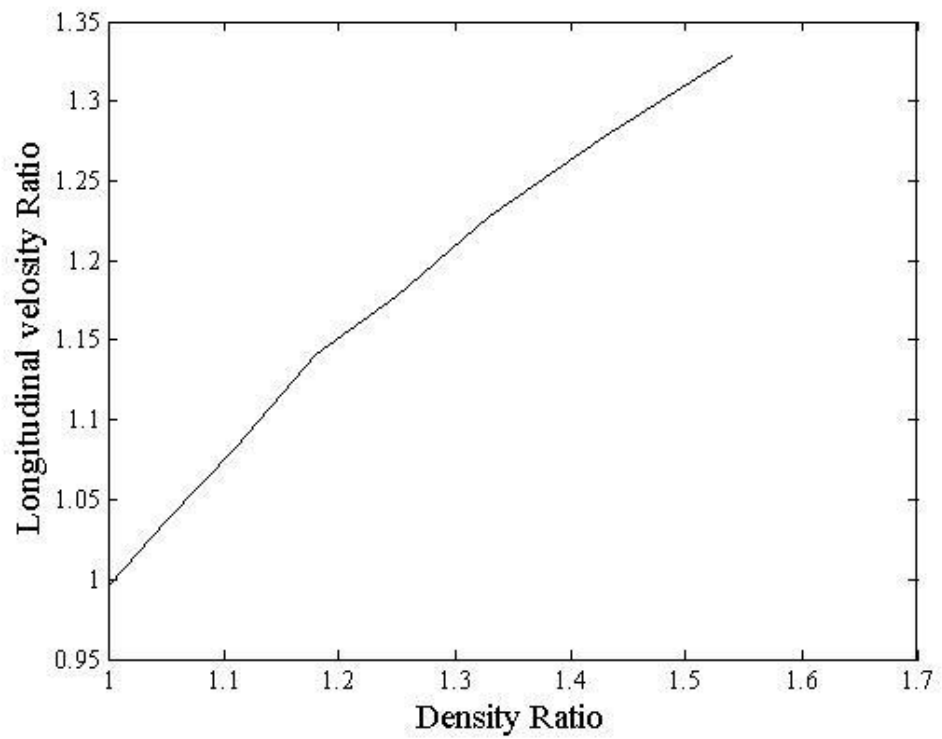

Fig. 6: Relation between longitudinal velocity ratio with Density ratio

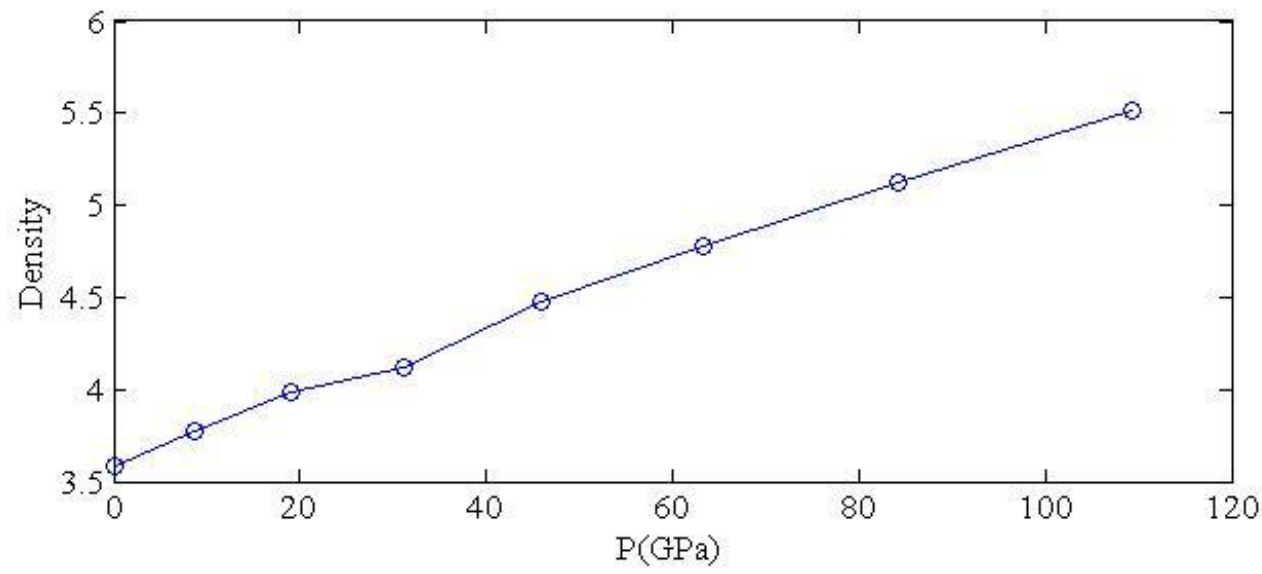

Fig. 7: Relation between Density and pressure

The density is linearly proportional with pressure. 


\section{High Pressure-Temperature Analysis}

The effects of high temp.-pressure on thermodynamic properties are calculated by using Modified Kumar EOS. The thermodynamic properties (thermal pressure Pth) thermal expansion ratio $\left(\alpha / \alpha_{\mathrm{o}}\right)$, thermal volume ratio $\mathrm{vp}_{\mathrm{p}} / \mathrm{V}_{\mathrm{o}}$, thermal bulk modulus ratio $\left(\mathrm{k} / \mathrm{k}_{\mathrm{o}}\right)$ are calculated by using equations $(12,14,16)$ which are shown in Figs. (8-11).

Fig. (8) shows the variation of thermal pressure with temperature at atmospheric pressure. It is increased linearly with increasing temperature, and at room temperature the thermal pressure is zero.

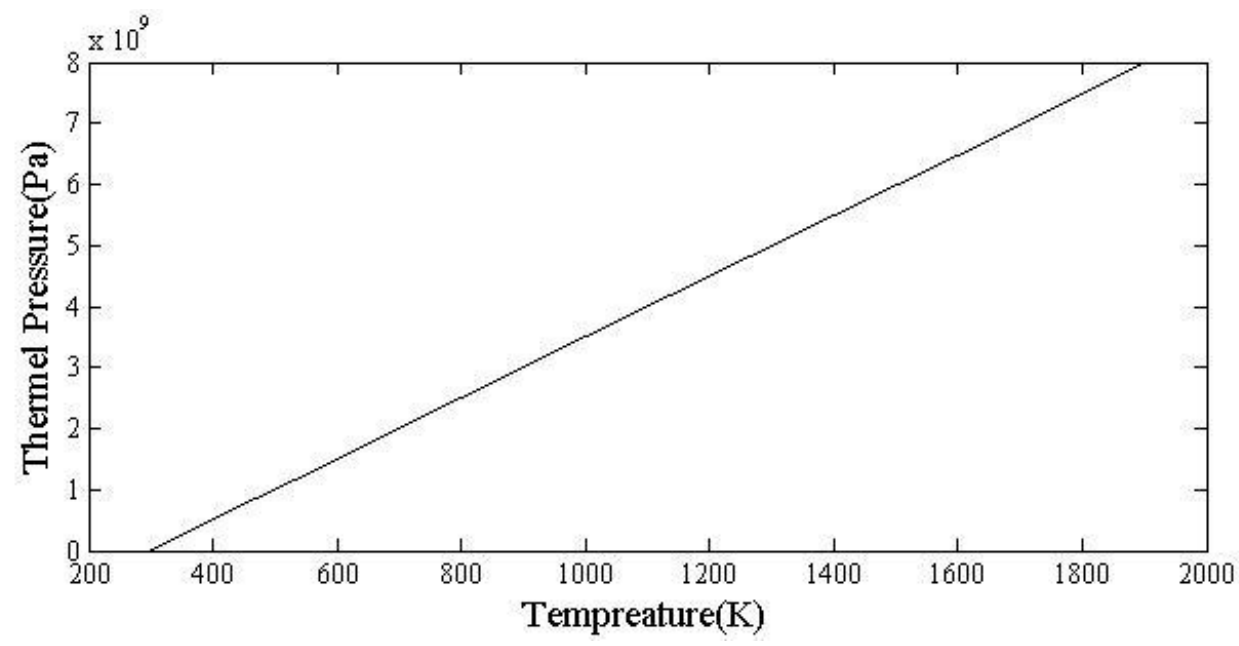

Fig. 8: The variation of thermal pressure with temperature

Fig. (9) shows the variation of the thermal expansion coefficient with temperature at defined pressure. At zero pressure, and at low temperature the thermal expansion increases slowly and at high temperature the curve increases gradually as shown in Fig. (9), at $p=2 \mathrm{GPa}$, the value of thermal expansion is lowered, and at $\mathrm{p}=5 \mathrm{GPa}$, the curve is more decreased, that is belong to the high pressure lower from the thermal expansion of inter- atomic distance and effect on the thermal volume as shown in Fig. (10).

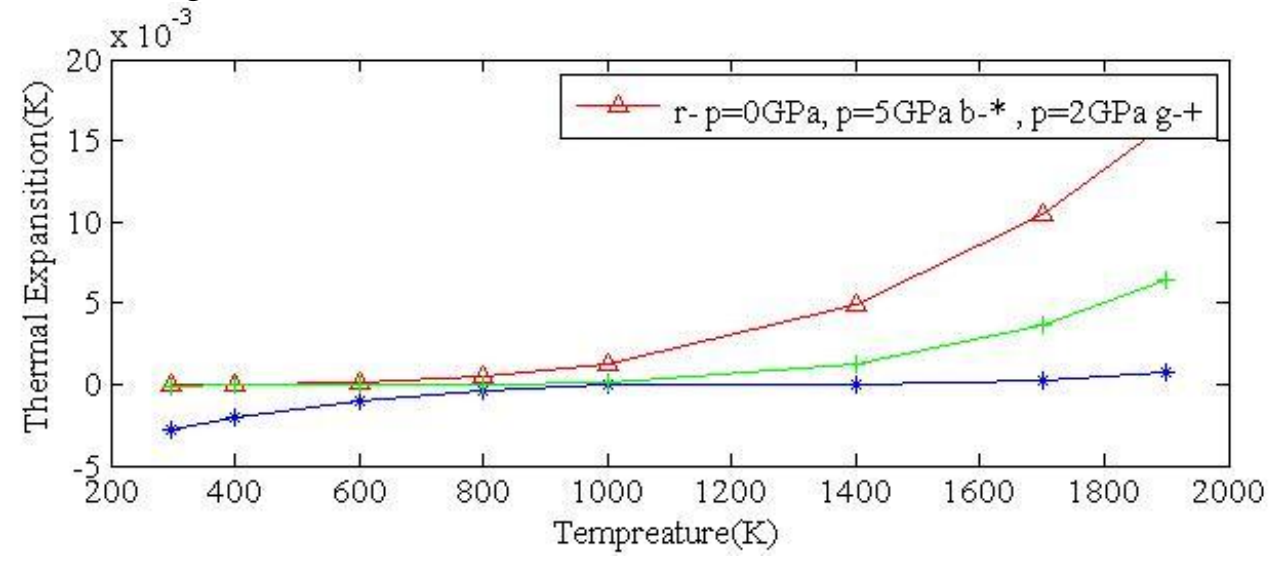

Fig. 9: The Variation of thermal expansion with temperature at high defined pressure

Fig. (10) shows the variation of thermal volume ratio $\left(\mathrm{vp}_{\mathrm{p}} / \mathrm{vo}\right)$ with increasing temperature at constant pressure. Results show that high pressure lesser from the thermal expansion of inter-atomic distance for $\mathrm{MgO}$ and this effect on volume. 


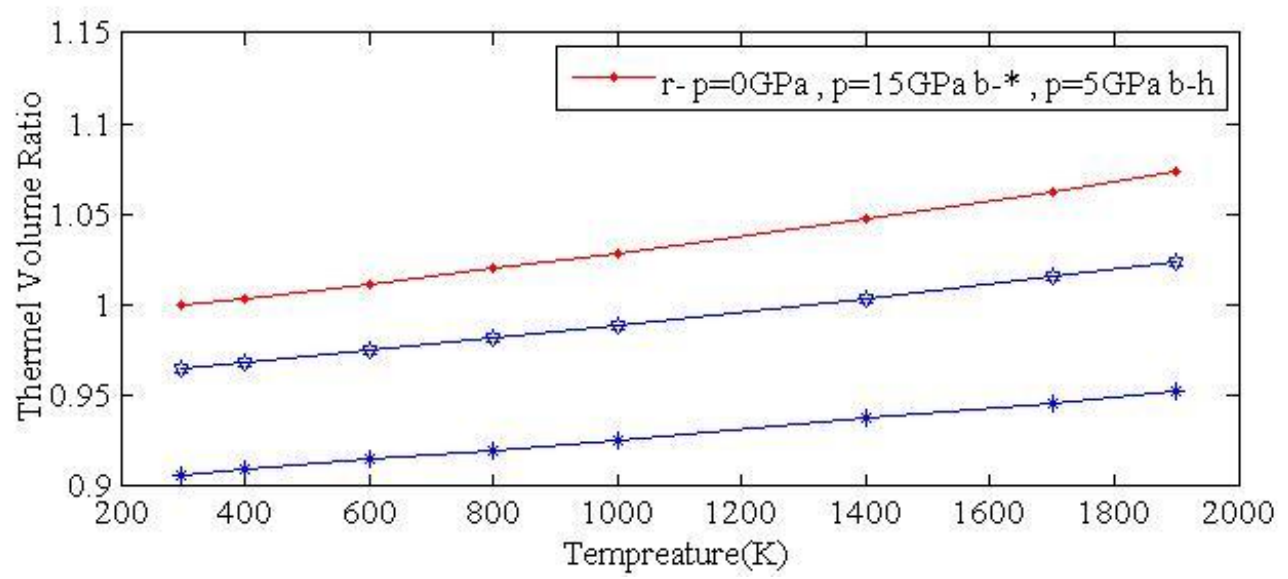

Fig. 10: The variation of thermal $\mathrm{vp}_{\mathrm{p} / \mathrm{v}}$ with temperature at defined pressure

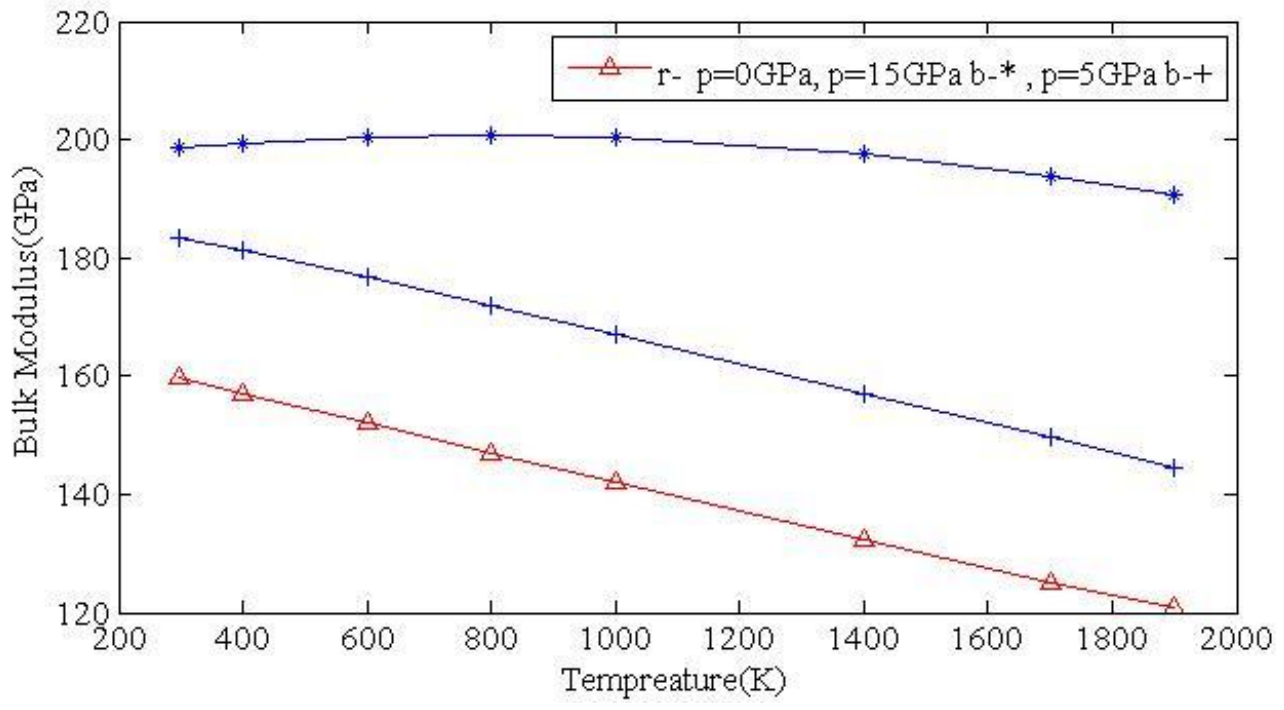

Fig. 11: The effect of temperature on Bulk modulus at defined pressure

The values of $\mathrm{K}$ are decreasing with the increases of temperature from $(0-2000 \mathrm{~K})$ under pressures $(15,5,0) \mathrm{GPa}$ and the behavior of bulk modulus with the increase of temperature, at low pressure $(0)$ is different as compared to high pressure $(15 \mathrm{GPa})$ and the shape of bulk modulus temperature curves under low and high pressure are different.

\section{CONCLUSION}

Shanker and Kumar EOSs results on $\mathrm{MgO}$ are consentient with the experimental data except the results related for solid sound velocity.

The average value of increasing of longitudinal value with the increase of pressure is faster than that of transverse velocity.

Figs. $(6,7)$ show that there are liner relation between (Transverse and Longitudinal velocities ratio) with $\mathrm{MgO}$ density.

Results show that high pressure lowers from the thermal expansion of the inter-atomic distance and this effect on volume.

The values of the bulk modules for $\mathrm{MgO}$ are increased with increasing pressure according to equation $(15,16)$ and the shape of the bulk modulus-temperature curves are different at low and high pressure. This is may be due to the manners of elastic constants which are different at low and high pressure. 
The examination of the manners of bulk modulus at different temperature and pressure for $\mathrm{MgO}$ may be useful in explaining the physical properties like Debye temperature, elastic wave velocity.

\section{RECOMMENDATION}

The present study is important for geophysical applications and physical research.

\section{REFERENCES}

Ahmad, J.F.; Mahmood, E.Sh. (2017). Thermo dynamical properties of copper under high pressure and different temperatures. Rafidian J. Sci., 26(1), 86-100.

Anderson, O.L. (1995). "Equation of State of Solids for Geophysical and Ceramic Science." Oxford University Press, New York. 214 p.

Born, M.; Huang, K. (1954). "Dynamical Theory of Crystal Lattices". Oxford University Press, Oxford.

Chopelas, A.; Reichhann, H. J.; Zhanf L. (1996). "Mineral Spectroscopy": A Tribute to Rofer C Burns. Geochemical society. Special Publication. No 5, pp.229-242.

Gaudoiu, R.; Foulkes, W. M. C. (2002). "Abinito calculations of bulk modulus and comparison with experiment". Physics B, 66 (5), 052104.

Kumar, M. (2002). Application of high pressure -high temperature equation of state for elastic properties of solid. Physics B. 311(3-4), 340-347.

Poirior, J. (2000). "Introduction to the Physics of the Earth's Interior". $2^{\text {nd }}$ ed., Cambridge university Press.

Singh, P.P.; Kumar, M. (2004). Temperature dependence of bulk modulus and second order elastic constant. Physics. B., 344( 1-4), 41-51.

Singh, S.P.; Gupta, S.; Goyal, S.C. (2007). Elastic properties of alkaline earth a under high pressure. Physics B., 391(2), 307-311.

Singh, M.; Singh, P. P.; Gupta, B. R. K.; Kumar, M. (2001). Temperature and pressure dependence of elastic constant . High temperatures -High pressures., 33(2), 199-206.

Upadhyay, A.K.; Sharma, B.S. (2011). Analysis of sound velocities and elastic moduli of some minerals. Indian J. Pure and Appl. Phys., 47, 362.

\section{دراسة نظرية لتأثير الضغط العالي على الخصائص المرنه والحرارية لاوكسيد المغتيسيوم}

$$
\begin{aligned}
& \text { الملخص } \\
& \text { استخدمت معادلة حالة Shanker المبنية على الجهد بين الذرات في حساب معاملات المرونة لاوكسيد المغنيسيوم } \\
& \text { (MgO) } \\
& \text { التجريبية وكذلك استخدمت نتائج معاملات المرونة في حساب سرعة الصوت داخل المادة الصلبة (الموجات الطولية والمستعرضة) }
\end{aligned}
$$

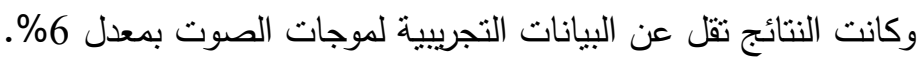

$$
\begin{aligned}
& \text { واستخدمت معادلة حالة Kumar المطوره المبنية على التحليلات الثيرموداينميكية والتمدد الحراري في حساب الانضغاطية } \\
& \text { الحرارية والحجم الحراري ومعامل التمدد الحراري والضغط الحراري تحت نأثثير الضغط العالي والدرجات الحرارة العالية وكانت } \\
& \text { النتائج منطابقة مع البيانات التجريبية. }
\end{aligned}
$$

الكلمات الدالة: اوكسيد المغنيسيوم، معادلات الحالة، معاملات المرونة، الخصائص الحرارية تحت الضغط العالي. 